\title{
A dental workforce strategy to make Australian public dental services more efficient
}

\author{
Tan Minh Nguyen ${ }^{1,2,3,4^{*}}$ (D), Utsana Tonmukayakul ${ }^{1}$ and Hanny Calache ${ }^{1,2,5,6}$
}

\begin{abstract}
Background: Dental services can be provided by the oral health therapy $(\mathrm{OHT})$ workforce and dentists. This study aims to quantify the potential cost-savings of increased utilisation of the OHT workforce in providing dental services for children under the Child Dental Benefits Schedule (CDBS). The CDBS is an Australian federal government initiative to increase dental care access for children aged 2-17 years.

Methods: Dental services billed under the CDBS for the 2013-2014 financial year were used. Two OHT-to-dentist workforce mix ratios were tested: Model A National Workforce (1:4) and Model B Victorian Workforce (2:3). The 30\% average salary difference between the two professions in the public sector was used to adjust the CDBS fee schedule for each type of service. The current 29\% utilisation rate of the CDBS and the government target of $80 \%$ were modelled.

Results: The estimated cost-savings under the current CDBS utilisation rate was AUD 26.5M and AUD 61.7M, for Models A and B, respectively. For the government target CDBS utilisation rate, AUD 73.2M for Model A and AUD 170.2M for Model B could be saved.

Conclusion: An increased utilisation of the OHT workforce to provide dental services under the CDBS would save costs on public dental service funding. The potential cost-savings can be reinvested in other dental initiatives such as outreach school-based dental check programmes or resource allocation to eliminate adult dental waiting lists in the public sector.

Keywords: Child health, Oral health, Public/private, Health economics, Health policy, Health sector reform, Health systems research, Health workers, National health service, Public policy
\end{abstract}

\section{Key messages}

- The costs to fund dental care under a universal healthcare system are expensive.

- Current Australian dental workforce models, which predominately rely on dentists to provide dental care, are inefficient to provide public dental services.

- Countries that are considering to embed dental services via universal healthcare systems should maximise the role of oral health therapists to provide more efficient public dental services.

\footnotetext{
* Correspondence: tan.nguyen@deakin.edu.au

${ }^{1}$ Deakin University, 75 Pigdons Road, Waurn Ponds, Victoria 3216, Australia

${ }^{2}$ University of Melbourne, Parkville, Australia

Full list of author information is available at the end of the article
}

\section{Introduction}

Oral diseases remain one of the most prevalent non-communicable chronic diseases that affect $90 \%$ of the world's population. Common oral diseases such as dental caries and periodontal disease share common risk factors with systemic diseases [1]. In Australia, oral conditions are the second most common cause of acute potentially preventable hospitalisations ( $\mathrm{PPH})$. Dental caries is the 10th most common cause of non-fatal burden of disease in Australia, totalling 71889 years lived with disability [2]. In the State of Victoria, Australia, about $64 \%$ of oral conditions related to acute PPH were directly attributed to dental caries [3].

In 2015-2016, there were 67266 PPH admissions for oral conditions [4]. PPH is defined as 'admissions that are potentially avoidable through timely and accessible, primary healthcare'. Globally, this measure is considered 
to be a 'high-level' health system performance indicator [5]. In 2016, the average cost of hospital in-patient episode of care for dental extractions and restorations was AUD 3041 [6]. Nationally, AUD 205M could potentially be saved if PPH admissions due to oral conditions could be averted [4]. The Australian health expenditure in 20142015 on oral health reached AUD 9.6B. Only $23.8 \%$ of this expenditure was contributed by government funding [7].

The goal to establish universal access to public dental care is often the topic of government debates [8]. Australian public dental services have traditionally been the responsibility of the state/territory governments. Two federal dental programmes, the Chronic Disease Dental Scheme (CDDS; 2007-2012) and the Medicare Teen Dental Plan (MTDP; 2008-2013), were previously introduced and implemented to address population inequalities on access to dental services. Evaluations of these programmes, however, have shown that (1) the CDDS was not cost-effective [9] and poorly utilised in rural and remote areas [10] and (2) the MTDP had low utilisation rates (highest rate recorded at 29\%) by eligible teenagers [11, 12] despite most claims have no out-of-pocket expenses. Reasons for low utilisation of both programmes, particularly in the rural and remote areas where the inequality is more prominent, remain unknown.

The focus on dental services for children has since expanded to include children aged $2-17$ years. This new scheme was branded the Child Dental Benefits Schedule (CDBS) in 2014 [13]. Under the CDBS, eligible children can claim up to AUD 1000 of dental benefits over 2 years. The CDBS included a wide range of dental treatment services such as restorations (fillings), removal of teeth and root canal treatment, which was not included in the MTDP. Two reviews of the CDBS share similar concerns to the MTDP, that is, regarding low utilisation rates $[13,14]$. The current rate at $29 \%$ falls short of the government target of $80 \%$ [13]. There is evidence that the Australian healthcare system is not achieving optimal oral health outcomes for children aged 0-12 years [15]. Currently, 29\% of children aged 5-6 have never visited a dental practitioner, and $26 \%$ of dental caries remain untreated in that population group [16].

The dental workforce in Australia consists of a range of dental practitioners that include dentists, dental specialists, dental hygienists (DH), dental therapists (DT), oral health therapists (OHT) and dental prosthetists. Dentists and dental specialists provide comprehensive dental services under the definition of dentistry. The scope of practice of dentists and dental specialists covers complex dental procedures such as root canal treatment, surgical removal of teeth and fabricating fixed dental prosthesis (dental implants, cast crowns and dental bridge work). DH, DT and OHT, which make up the oral health therapy workforce, have a more narrow scope of practice and are focused on prevention. Their scope of practice is limited to routine dental examinations, preventive procedures, the placement of non-complex restorations (fillings) and non-surgical periodontal treatment (removal of plaque and calculus from teeth).

In general, dentists and the oral health therapy workforce manage the two most common oral diseases, dental caries and periodontal disease, at various levels of complexity. The length of training for dentists is between 5 and 7 years (5-year bachelor degree or 3-year bachelor degree combined with a 4-year postgraduate degree) compared to 3-year bachelor degree for OHT. OHT have combined skillsets of DH and DT. Traditionally, DH and DT qualifications were either a 2-year certificate or a 2-year diploma. However, DT training programmes no longer exist in Australia due to the emergence of training dual-qualified OHT $[17,18]$.

Dental services provided to children have been the historical legacy of the DT role in addressing children's unmet dental needs [19]. The New Zealand model for utilising DT in school-based services started in 1921 and has rapidly spread to 54 other countries including Australia [20]. Several government reports identified the importance to better utilise the OHT workforce to their full scope of practice [21-23]. One possible reason for low utilisation rates of the MTDP and CDBS dental programmes may be due to an existing inefficient dental workforce model. In this paper, $\mathrm{DH}, \mathrm{DT}$ and OHT are collectively referred to as the OHT workforce unless otherwise explicitly stated.

Under the current workforce skill mix ratio, there is a reliance on the 'over-qualified' dentist workforce to provide less complex dental services. Nationally, the dental workforce comprises of $21 \%$ of OHT and $79 \%$ for dentists [24], an OHT-to-dentist workforce skill mix ratio of 1:4. In the dental public sector in Victoria, dentists account for $61 \%$ of the dental workforce, an OHT-to-dentist workforce skill mix ratio of 2:3. Dentists, the most expensive member of the dental team [22], have been the primary providers for the CDDS, MTDP and CDBS. Therefore, this study aims to quantify the potential cost-savings of a hypothetical increased utilisation of the OHT workforce for providing dental services via the CDBS dental programme.

\section{Methods}

De-identifiable data used in the present study are publicly available. Therefore, ethics approval was not required. This research was performed according to principles from the Declaration of Helsinki.

\section{Data source}

Data on dental services billed under the CDBS for the 2014-2015 year was retrieved electronically and publicly available [25]. However, the data does not provide information as to who provided the service. Dental providers 
were identified by using two OHT-to-dentist workforce skill mix ratios and applying a salary difference between the two dental professions to adjust the total CDBS claims for each ratio.

\section{Salary difference}

The average salary difference between OHT and dentist employed in the public sector was used from eight state and territory jurisdictions (Table 1). The 'on-cost' of employment was not used because it is proportionally different and would not affect the average salary difference. The estimated salary difference is $30 \%$, which means the OHT workforce would earn $30 \%$ less than dentists for dental services within their scope of practice (Table 2 and Appendix).

\section{Workforce models}

Two OHT-to-dentist workforce skill mix ratios were considered. For Model A National Workforce, the cost-savings was estimated using the Australian dental workforce skill mix ratio of 1:4 [24]. For Model B Victorian Workforce, the Victorian public sector dental workforce skill mix ratio of 2:3 was applied [22]. The proportion of each type of dental service provided was assigned against the type of dental provider by percentage (Table 3). This modelling approach was adopted in previous work [26].

\section{Scenario analysis and discounting}

The cost effects were modelled according to the current CDBS utilisation rate of $29 \%$. A one-way sensitivity analysis was performed for the government target of $80 \%$ CDBS utilisation rate. All costs were calculated in 2014 Australian dollars. A discount rate did not apply since costs are consumed within 1 year. Data analysis was performed using Excel 2016 (Microsoft Corporation).

\section{Assumptions}

The following assumptions were applied in this analysis:

Table 1 The 2013/2014 salary differential between OHT and dentists employed in the public sector, by state and territory in Australia

\begin{tabular}{ll}
\hline State/territory & Salary difference (\%) \\
\hline Australian Capital Territory [57] & 15.6 \\
New South Wales $[58,59]$ & 29.8 \\
Northern Territory $[60,61]$ & 20.0 \\
Queensland [62] & 35.6 \\
South Australia [63] & 41.0 \\
Tasmania $[64,65]$ & 48.3 \\
Victoria $[66,67]$ & 16.0 \\
Western Australia $[68,69]$ & 33.8 \\
Mean salary differential & 30.0 \\
\hline
\end{tabular}

Table 2 Summary of dental treatment services that can be provided by the dental practitioner divisions

\begin{tabular}{lllll}
\hline Service type & DH & DT & OHT & Dentist \\
\hline Diagnostics & $\checkmark$ & $\checkmark$ & $\checkmark$ & $\checkmark$ \\
Preventive & $\checkmark$ & $\checkmark$ & $\checkmark$ & $\checkmark$ \\
Periodontics & $\checkmark$ & $\boldsymbol{x}$ & $\checkmark$ & $\checkmark$ \\
Oral surgery & $\boldsymbol{x}$ & 88311 and & 88311 and & $\checkmark$ \\
& & 88316 only & 88316 only & \\
Endodontics & $\boldsymbol{x}$ & 88411 and & 88411 and & $\checkmark$ \\
Restorative services & $\boldsymbol{x}$ & $\checkmark 8414$ only & 88414 only & \\
Prosthodontics & $\boldsymbol{x}$ & $\boldsymbol{x}$ & $\checkmark$ & $\checkmark$ \\
General services & 88911 only & 88911 only & 88911 only & $\checkmark$
\end{tabular}

88311 - extraction of tooth (first tooth extracted on day)

88316-additional extraction of tooth

88411 - direct pulp capping

88414 -pulpotomy

88911 - palliative care

$D H$ dental hygienist, $D T$ dental therapist, $O H T$ oral health therapist

- The type and number of dental services provided to children 2-17 years are evenly distributed across the state and territory jurisdictions.

- Dental services were weighted according to each type of provider by workforce size percentage.

- All the children receiving dental treatment received at least a comprehensive oral examination (item code 88011).

\section{Results}

The total CDBS expenditure in the 2014/2015 year was AUD 537M. A summary of the cost allocation according to dental service type and age groups is shown in Table 4. The total costs for the $0-4,5-14$ and 15-17 age groups were AUD 18.8M, AUD 376.5M and AUD 141.8M, respectively. The projected total costs under Model A National Workforce and Model B Victorian Workforce are AUD 511M and AUD 475M resulting in the potential cost-savings of AUD $26.5 \mathrm{M}$ and AUD $61.7 \mathrm{M}$, respectively. For the one-way sensitivity analysis calculated using a 2.7 -fold increase in dental service utilisation, the potential cost-savings would be AUD $73.2 \mathrm{M}$ and AUD $170.2 \mathrm{M}$, respectively. A summary of the cost allocation for each type of provider is shown in Table 5.

Table 3 Dental service provision was weighted for Model A National and Model B Victoria. The dental workforce ratio for Model A and Model B is approximately 1:4 and 2:3, respectively

\begin{tabular}{lll}
\hline Models of workforce distribution & OHT & Dentist \\
\hline Model A National (1:4) & $19.6 \%$ & $80.4 \%$ \\
Model B Victoria (2:3) & $39 \%$ & $61 \%$
\end{tabular}

$\mathrm{OHT}$ oral health therapist 
Table 4 The total cost for Medicare benefits claims under the CDBS by dental service type in the 2014-2015 financial year

\begin{tabular}{|c|c|c|c|c|}
\hline Service type & $\begin{array}{l}0-4 \text { age } \\
\text { group (A\$) }\end{array}$ & $\begin{array}{l}5-14 \text { age } \\
\text { group (A\$) }\end{array}$ & $\begin{array}{l}15-17 \text { age } \\
\text { group (A\$) }\end{array}$ & Subtotal (A\$) \\
\hline aqnos & 36 & 50479640 & 18764669 & 345 \\
\hline eventive & 4348506 & 121296380 & 44984411 & 170 \\
\hline eriodontics & 11740 & 246037 & 240960 & 498738 \\
\hline ral surgery & 430620 & 39108772 & 8789368 & 483 \\
\hline dodontics & 125322 & 4551556 & 3583657 & 8260535 \\
\hline Restorative services & 8503913 & 158133500 & 64770100 & 231407513 \\
\hline Prosthodontics & 3220 & 44 & 30 & 69 \\
\hline ener & 168618 & 2292021 & 329127 & 2789766 \\
\hline Total & 18835975 & 376487410 & 141771720 & 537095105 \\
\hline
\end{tabular}

$D H$ dental hygienist, $D T$ dental therapist, $O H T$ oral health therapist

\section{Discussion}

This study estimated the potential economic benefits for utilising the OHT workforce from the Australian healthcare system perspective for dental services under the CDBS as a case study. The oral health workforce profile has changed since the landmark 1993 Nuffield Foundation report recommended the establishment of the 'oral health therapist', to complement existing dental services mainly provided by dentists [27]. It is widely recognised that the OHT workforce provides high-quality and cost-effective dental services within their scope of practice, which enables dentists to focus on more complex procedures [28, 29].

Oral health workforce modelling in the United Kingdom shows there is a significant demand for OHT in optimising the dental workforce skill mix cost-effectively [30-32]. For example, only $30 \%$ of dentists would be required, and the number of DT would need to increase tenfold to achieve $52 \%$ in salary cost-savings [32]. Positive associations were identified for increasing productivity among dental practices that employ $\mathrm{DH}$ in the US private sector [33, 34]. More recently, there is a growing demand for training DT in the United States of America to meet unmet community needs for children, low-income families and rural communities [19, 35-37].

The range of dental services provided by the OHT workforce is diverse $[17,18]$ which could result in various levels of economic benefits for the community if the OHT workforce plays a critical role in primary healthcare. An independent policy report on public dental funding noted that changing the oral health workforce favouring OHT over dentists would reduce the cost of subsequent phases of a universal dental scheme [38]. The State of Victoria is one example where the dental workforce is more cost-effectively utilised than the national workforce skill mix due to greater utilisation of the OHT workforce.

This paper quantified the potential cost-savings if public funded dental services for children reflected the 30\% salary difference between the OHT and dentist based on the CDBS fee schedule. From our modelling work, there are three proposals for consideration:

- Option 1: Status quo: the government will continue to pay benefits at dentists' fee rates for dental services provided by OHT. The monetary surplus is retained as 'profit', which can be an incentive for not-for-profit public dental services to deliver more services.

- Option 2: Introduce a two-tier CDBS fee structure to reflect the $30 \%$ salary differential between OHT and dentists. In other words, dental services delivered by OHT are $30 \%$ cheaper than the same service provided by dentists. Under this option, it is necessary for OHT to obtain a Medicare provider number to bill for services directly. Currently, OHT can only use a dentists' Medicare provider number. Eligible children and adolescents would be able to access more services under the AUD 1000 2-year capped allowance if their care is provided predominately by the OHT workforce.

- Option 3: Introduce an overall 30\% reduction in CDBS fee structure: the cost-savings would be more

Table 5 The estimated costs for dental services provided under the CDBS against the type of dental service for Models A and B

\begin{tabular}{|c|c|c|c|c|c|c|c|}
\hline \multirow{2}{*}{$\begin{array}{l}\text { Type of dental } \\
\text { service }\end{array}$} & \multicolumn{4}{|c|}{ Model A (National 1:4) } & \multicolumn{3}{|c|}{ Model B (Victoria 2:3) } \\
\hline & $\mathrm{DH}(\mathrm{A} \$)$ & DT/OHT (A\$) & Dentist (A\$) & Subtotal (A\$) & $\mathrm{OHT}(\mathrm{A} \$)$ & Dentist (A\$) & Subtotal (A\$) \\
\hline Diagnostics & 3411108 & 6784314 & 59861769 & 70057191 & 20249553 & 45437891 & 65687444 \\
\hline Preventive & 7785212 & 15483921 & 137124425 & 160393559 & 46215798 & 104083871 & 150299669 \\
\hline Periodontics & 22756 & 45258 & 400805 & 468819 & 135086 & 304230 & 439316 \\
\hline Oral surgery & 0 & 4172480 & 42320870 & 46493349 & 11635674 & 31574730 & 43210404 \\
\hline Endodontics & 0 & 223659 & 7938492 & 8162151 & 623710 & 7362463 & 7986174 \\
\hline Restorative services & 0 & 22474406 & 199046958 & 221521364 & 62673728 & 141164565 & 203838293 \\
\hline Prosthodontics & 0 & 0 & 692152 & 692152 & 0 & 692152 & 692152 \\
\hline General services & 7011 & 13943 & 2759595 & 2780549 & 41617 & 2729842 & 2771459 \\
\hline Total & 11226086 & 49197981 & 450145066 & 510569133 & 141575166 & 333349744 & 474924910 \\
\hline
\end{tabular}

$D H$ dental hygienist, $D T$ dental therapist, $O H T$ oral health therapist 
significant than option 2. However, this option could create a disincentive for dentists to provide dental services under their scope of practice to the CDBS eligible population and potentially widen the gap of the inequity of access to public dental care among socioeconomic disadvantage population.

Although funding for dental treatment is an essential part of the healthcare system, there are alternative preventive models of care that are worth considering. For example, an outreach school-based dental check-up programme provided by the OHT workforce increased dental utilisation for Victorian public dental services for children from low-income families [15, 39, 40]. An economic evaluation determined that the intervention was less costly and more clinically effective than standard care [40]. Another strategy that could be adopted in Australia is enabling non-dental practitioners to provide oral health prevention services. Positive impacts have been demonstrated in both the Australian context $[41,42]$ and the United States of America [43-48]. Studies from the United Kingdom [49-51] and Sweden [52] currently capitalise on the expanded role of dental assistants to provide preventive services to children. This model is currently being explored in Victoria $[22,53]$.

Another potential resource allocation from the estimated cost-saving could be reinvestment to eliminate adult public dental waiting list, which can be up to 3 years [23]. Adult public dental waiting lists are a major problem in Australia dental care system since it is reliant on government funding. It is estimated that AUD 46.6M (AUD 50M-100M) is required to reduce the 2013 Australian public dental waiting list from 263043 to zero; costs would increase to AUD 111.4M if dental services were contracted to the private sector [54]. The cost-saving based on Model A could be allocated to this, but only half of the required budget will be met, whereas the cost-saving from Model B will not only set the waiting list to zero but also provide a surplus of AUD 15.1M. There is also an additional economic benefit for utilising the OHT workforce since the model on costs required to manage the 2013 waiting only included the cost of dentists to provide adult dental services. International countries considering to fund or expand dental services under a universal healthcare system can make public dental services more affordable through the maximal utilisation of the OHT workforce.

Although the potential cost-savings are obvious, it remains unknown that greater utilisation of the OHT workforce would increase CDBS uptake. Observations from past government reviews on the MTDP and CDBS dental programmes suggest that consumer-driven demand is relatively low which means dental cost subsidisation may not improve access to dental care [12-14]. However, the supply of the dental profession and willingness to participate in federal dental schemes is also critical. Greater dentist participation in Medicaid for children's dental care in the United States of America has been associated with dentist density and high reimbursement rates [55]. Naturally, if dentists are remunerated better by not participating in subsidised schemes, utilisation rates for federal dental schemes would be less than ideal. Hence, increasing the OHT workforce, a workforce that may have a greater willingness to participate would potentially boost the CDBS uptake rate. Unequivocally, the global literature review of utilising DT in public school-based programmes increases access to dental care for children compared to the US private practice dentist-led model $[19,56]$.

Furthermore, the goal to implement universal dental care goes beyond the fee structures for dental practitioners and an adequate level of government funding. It is unknown whether there is sufficient infrastructure to provide dental services through the public and private sector. Therefore, the costs to establish accessible dental clinics by consumers must be considered but is beyond the scope of this paper. These costs could be offset by having a paradigm shift in the way the federal government currently funds the number of tertiary education programmes for the OHT workforce and dentists. A typical postgraduate dental programme costs more than AUD 300000 . Proportionally, domestic OHT students account for $24 \%$ of the combined OHT and dental student enrolment [26].

Alternatively, other strategies could make public dental services more affordable under a universal healthcare system. Firstly, since OHT qualifications require less time for training. The Australian government could consider gradually reducing the number of students enrolled in dental programmes. The decreasing government-supported domestic dental student enrolment would result in a reduction in government expenditure on tertiary education. Secondly, to address an inefficient workforce skill mix ratio, a rapid increase in OHT numbers could be achieved by replacing dental student positions with OHT student positions. As a result, an increased overall supply of OHT in the workforce could facilitate a more affordable investment in establishing universal dental care compared to the status quo. The major assumptions discussed above qualitatively discuss some of the main limitations of our study. Therefore, the results should be interpreted with caution.

\section{Conclusion}

In summary, the potential cost-savings from the publicly funded CDBS dental programme for children can be achieved through maximal utilisation of the OHT workforce from the Australian healthcare perspective. Policy-decision makers should consider the important role of the OHT workforce in achieving universal dental care. The potential cost-savings could be reinvested in other dental initiatives that would increase access to dental care. 
Table 6 The service provision weights of individual dental services according to the dental practitioner division scope of practice for Models A and B

\begin{tabular}{|c|c|c|c|c|c|c|}
\hline \multirow[t]{2}{*}{ Item code } & \multirow[t]{2}{*}{ Service description } & \multicolumn{3}{|c|}{$\begin{array}{l}\text { Model A } \\
\text { National }\end{array}$} & \multicolumn{2}{|c|}{ Model B Victoria } \\
\hline & & $\overline{\mathrm{DH}}$ & $\begin{array}{l}\mathrm{OHT} / \\
\mathrm{DT}\end{array}$ & Dentist & $\mathrm{OHT}$ & Dentist \\
\hline 88011 & Comprehensive oral exam & 0.0657 & 0.131 & 0.804 & 0.390 & 0.610 \\
\hline 88012 & Periodic oral examination & 0.0657 & 0.131 & 0.804 & 0.390 & 0.610 \\
\hline 88013 & Oral examination_limited & 0.0657 & 0.131 & 0.804 & 0.390 & 0.610 \\
\hline 88022 & Intraoral periapical or bitewing radiograph_-per exposure & 0.0657 & 0.131 & 0.804 & 0.390 & 0.610 \\
\hline 88025 & Intraoral radiograph_occlusal, maxillary, mandibular-per exposure & 0.0657 & 0.131 & 0.804 & 0.390 & 0.610 \\
\hline 88111 & Removal of plaque and/or stain & 0.0657 & 0.131 & 0.804 & 0.390 & 0.610 \\
\hline 88114 & Removal of calculus_first visit & 0.0657 & 0.131 & 0.804 & 0.390 & 0.610 \\
\hline 88115 & Removal of calculus_-subsequent visit & 0.0657 & 0.131 & 0.804 & 0.390 & 0.610 \\
\hline 88121 & Topical application of remineralisation and/or cariostatic agents, one treatment & 0.0657 & 0.131 & 0.804 & 0.390 & 0.610 \\
\hline 88161 & Fissure and/or tooth surface sealing — per tooth (first four services on a day) & 0.0657 & 0.131 & 0.804 & 0.390 & 0.610 \\
\hline 88162 & Fissure and/or tooth surface sealing_-per tooth (subsequent services) & 0.0657 & 0.131 & 0.804 & 0.390 & 0.610 \\
\hline 88213 & Treatment of acute periodontal infection - per visit & 0.0657 & 0.131 & 0.804 & 0.390 & 0.610 \\
\hline 88221 & Clinical periodontal analysis and recording & 0.0657 & 0.131 & 0.804 & 0.390 & 0.610 \\
\hline 88311 & Removal of a tooth or part(s) thereof-first tooth extracted on a day & 0 & 0.140 & 0.860 & 0.390 & 0.610 \\
\hline 88314 & Sectional removal of a tooth or part(s) thereof-first tooth extracted on a day & 0 & 0 & 1 & 0 & 1 \\
\hline 88316 & $\begin{array}{l}\text { Additional extraction requiring removal of a tooth or part(s) thereof, or sectional } \\
\text { removal of a tooth }\end{array}$ & 0 & 0.140 & 0.860 & 0.390 & 0.610 \\
\hline 88322 & $\begin{array}{l}\text { Surgical removal of a tooth or tooth fragment not requiring removal of bone or } \\
\text { tooth division - first tooth extracted on a day }\end{array}$ & 0 & 0 & 1 & 0 & 1 \\
\hline 88323 & $\begin{array}{l}\text { Surgical removal of a tooth or tooth fragment requiring removal of bone-first } \\
\text { tooth extracted on a day }\end{array}$ & 0 & 0 & 1 & 0 & 1 \\
\hline 88324 & $\begin{array}{l}\text { Surgical removal of a tooth or tooth fragment requiring both removal of bone } \\
\text { and tooth division - first tooth extracted on a day }\end{array}$ & 0 & 0 & 1 & 0 & 1 \\
\hline 88326 & Additional extraction requiring surgical removal of a tooth or tooth fragment & 0 & 0 & 1 & 0 & 1 \\
\hline 88351 & Repair of skin and subcutaneous tissue or mucous membrane & 0 & 0 & 1 & 0 & 1 \\
\hline 88384 & Repositioning of displaced tooth/teeth—per tooth & 0 & 0 & 1 & 0 & 1 \\
\hline 88386 & Splinting of displaced tooth/teeth—per tooth & 0 & 0 & 1 & 0 & 1 \\
\hline 88387 & Replantation and splinting of a tooth & 0 & 0 & 1 & 0 & 1 \\
\hline 88392 & Drainage of abscess & 0 & 0 & 1 & 0 & 1 \\
\hline 88411 & Direct pulp capping & 0 & 0.140 & 0.860 & 0.390 & 0.610 \\
\hline 88412 & Incomplete endodontic therapy (tooth not suitable for further treatment) & 0 & 0 & 1 & 0 & 1 \\
\hline 88414 & Pulpotomy & 0 & 0.140 & 0.860 & 0.390 & 0.610 \\
\hline 88415 & Complete chemo-mechanical preparation of root canal—one canal & 0 & 0 & 1 & 0 & 1 \\
\hline 88416 & Complete chemo-mechanical preparation of root canal_each additional canal & 0 & 0 & 1 & 0 & 1 \\
\hline 88417 & Root canal obturation—one canal & 0 & 0 & 1 & 0 & 1 \\
\hline 88418 & Root canal obturation_-each additional canal & 0 & 0 & 1 & 0 & 1 \\
\hline 88419 & Extirpation of pulp or debridement of root canal(s)—emergency or palliative & 0 & 0 & 1 & 0 & 1 \\
\hline 88421 & Resorbable root canal filling_-primary tooth & 0 & 0 & 1 & 0 & 1 \\
\hline 88455 & Additional visit for irrigation and/or dressing of the root canal system—-per tooth & 0 & 0 & 1 & 0 & 1 \\
\hline 88458 & Interim therapeutic root filling-per tooth & 0 & 0 & 1 & 0 & 1 \\
\hline 88511 & Metallic restoration-one surface-direct & 0 & 0.140 & 0.860 & 0.390 & 0.610 \\
\hline 88512 & Metallic restoration-two surfaces-direct & 0 & 0.140 & 0.860 & 0.390 & 0.610 \\
\hline 88513 & Metallic restoration-three surfaces-direct & 0 & 0.140 & 0.860 & 0.390 & 0.610 \\
\hline 88514 & Metallic restoration—four surfaces_-direct & 0 & 0.140 & 0.860 & 0.390 & 0.610 \\
\hline
\end{tabular}


Table 6 The service provision weights of individual dental services according to the dental practitioner division scope of practice for Models A and B (Continued)

\begin{tabular}{|c|c|c|c|c|c|c|}
\hline \multirow[t]{2}{*}{ Item code } & \multirow[t]{2}{*}{ Service description } & \multicolumn{3}{|c|}{$\begin{array}{l}\text { Model A } \\
\text { National }\end{array}$} & \multicolumn{2}{|c|}{ Model B Victoria } \\
\hline & & $\mathrm{DH}$ & $\begin{array}{l}\text { OHT/ } \\
\text { DT }\end{array}$ & Dentist & $\mathrm{OHT}$ & Dentist \\
\hline 88515 & Metallic restoration—five surfaces_direct & 0 & 0.140 & 0.860 & 0.390 & 0.610 \\
\hline 88521 & Adhesive restoration—one surface—anterior tooth—direct & 0 & 0.140 & 0.860 & 0.390 & 0.610 \\
\hline 88522 & Adhesive restoration — two surfaces—anterior tooth—direct & 0 & 0.140 & 0.860 & 0.390 & 0.610 \\
\hline 88523 & Adhesive restoration—-three surfaces_-anterior tooth—direct & 0 & 0.140 & 0.860 & 0.390 & 0.610 \\
\hline 88524 & Adhesive restoration—four surfaces_-anterior tooth—direct & 0 & 0.140 & 0.860 & 0.390 & 0.610 \\
\hline 88525 & Adhesive restoration—five surfaces_-anterior tooth—direct & 0 & 0.140 & 0.860 & 0.390 & 0.610 \\
\hline 88531 & Adhesive restoration—one surface—posterior tooth—direct & 0 & 0.140 & 0.860 & 0.390 & 0.610 \\
\hline 88532 & Adhesive restoration— two surfaces—-posterior tooth—direct & 0 & 0.140 & 0.860 & 0.390 & 0.610 \\
\hline 88533 & Adhesive restoration—three surfaces—posterior tooth—direct & 0 & 0.140 & 0.860 & 0.390 & 0.610 \\
\hline 88534 & Adhesive restoration—four surfaces—-posterior tooth—direct & 0 & 0.140 & 0.860 & 0.390 & 0.610 \\
\hline 88535 & Adhesive restoration—five surfaces_-posterior tooth—direct & 0 & 0.140 & 0.860 & 0.390 & 0.610 \\
\hline 88572 & Provisional (intermediate/temporary) restoration — per tooth & 0 & 0.140 & 0.860 & 0.390 & 0.610 \\
\hline 88574 & Metal band & 0 & 0.140 & 0.860 & 0.390 & 0.610 \\
\hline 88575 & Pin retention-per pin & 0 & 0.140 & 0.860 & 0.390 & 0.610 \\
\hline 88576 & Metallic crown-preformed & 0 & 0.140 & 0.860 & 0.390 & 0.610 \\
\hline 88579 & Bonding of tooth fragment & 0 & 0.140 & 0.860 & 0.390 & 0.610 \\
\hline 88597 & Post-direct & 0 & 0 & 1 & 0 & 1 \\
\hline 88721 & Partial maxillary denture-resin, base only & 0 & 0 & 1 & 0 & 1 \\
\hline 88722 & Partial mandibular denture-resin, base only & 0 & 0 & 1 & 0 & 1 \\
\hline 88731 & Retainer-per tooth & 0 & 0 & 1 & 0 & 1 \\
\hline 88733 & Tooth/teeth (partial denture) & 0 & 0 & 1 & 0 & 1 \\
\hline 88736 & Immediate tooth replacement-per tooth & 0 & 0 & 1 & 0 & 1 \\
\hline 88741 & Adjustment of a denture & 0 & 0 & 1 & 0 & 1 \\
\hline 88761 & Reattaching pre-existing clasp to denture & 0 & 0 & 1 & 0 & 1 \\
\hline 88762 & Replacing/adding clasp to denture-per clasp & 0 & 0 & 1 & 0 & 1 \\
\hline 88764 & Repairing broken base of a partial denture & 0 & 0 & 1 & 0 & 1 \\
\hline 88765 & Replacing/adding new tooth on denture-per tooth & 0 & 0 & 1 & 0 & 1 \\
\hline 88766 & Reattaching existing tooth on denture--per tooth & 0 & 0 & 1 & 0 & 1 \\
\hline 88768 & $\begin{array}{l}\text { Adding tooth to partial denture to replace an extracted or decoronated } \\
\text { tooth-per tooth }\end{array}$ & 0 & 0 & 1 & 0 & 1 \\
\hline 88776 & Impression—dental appliance repair/modification & 0 & 0 & 1 & 0 & 1 \\
\hline 88911 & Palliative care & 0.0657 & 0.131 & 0.804 & 0.390 & 0.610 \\
\hline 88942 & Sedation-intravenous & 0 & 0 & 1 & 0 & 1 \\
\hline 88943 & Sedation-inhalation & 0 & 0 & 1 & 0 & 1 \\
\hline
\end{tabular}

$\overline{D H}$ dental hygienist, $D T$ dental therapist, $\mathrm{OHT}$ oral health therapist 


\section{Abbreviations}

CDBS: Child Dental Benefits Schedule; CDDS: Chronic Disease Dental Scheme; DH: Dental hygienist; DT: Dental therapist; MTDP: Medicare Teen Dental Plan; OHT: Oral health therapist; PPH: Potentially preventable hospitalisations; UK: United Kingdom; US: United States

\section{Acknowledgements}

The authors wish to acknowledge the contributions of Katy Theodore in preparing this manuscript.

\section{Funding}

Not applicable.

\section{Availability of data and materials}

Data is publicly available on the Australian Government website.

\section{Authors' contributions}

TMN was responsible for the conceptual design, data analysis and manuscript preparation. All other authors contributed critically to the manuscript content and revisions and approved the final content for peer-review.

\section{Ethics approval and consent to participate}

Not applicable.

\section{Consent for publication}

Not applicable.

\section{Competing interests}

The authors declare that they have no competing interests.

\section{Publisher's Note}

Springer Nature remains neutral with regard to jurisdictional claims in published maps and institutional affiliations.

\section{Author details}

'Deakin University, 75 Pigdons Road, Waurn Ponds, Victoria 3216, Australia. ${ }^{2}$ University of Melbourne, Parkville, Australia. ${ }^{3}$ Peninsula Health, Frankston, Australia. ${ }^{4}$ Coburg Hill Oral Care, Hill, Coburg, Australia. ${ }^{5}$ La Trobe University, Bendigo, Australia. ${ }^{6}$ North Richmond Community Health, North Richmond, Australia.

Received: 30 August 2018 Accepted: 2 May 2019

Published online: 30 May 2019

\section{References}

1. Jin L, Lamster I, Greenspan J, Pitts N, Scully C, Warnakulasuriya S. Global burden of oral diseases: emerging concepts, management and interplay with systemic health. Oral Dis. 2016;22(7):609-19.

2. Australian Institute of Health and Welfare. Australian Burden of Disease Study: impact and causes of illness and death in Australia 2011, Australian Burden of Disease Study Series no. 3. BOD 4. Canberra: Australian Institute of Health and Welfare; 2016.

3. Rogers JG. Dental hospitalisation of Victorian children and young adults prevalence, determinants, impacts and policy implications, in Melbourne Dental School. Australia: University of Melbourne; 2016.

4. Australian Institute of Health and Welfare. Admitted patient care 2015-16: Australian hospital statistics, Health Services Series no.75. Cat. no. HSE 185. Canberra: Australian Institute of Health and Welfare; 2017.

5. Falster M, Jorm L. A guide to the potentially preventable hospitalisations indicator in Australia. Sydney: Centre for Big Data Research in Health, University of New South Wales in consultation with Australian Commission on Safety and Quality in Health Care and Australian Institute of Health and Welfare: 2017.

6. Independent Hospital Pricing Authority. National Hospital Cost Data Collection, Australian Public Hospitals Cost Report 2013-2014 Round 18. 2016.

7. Australian Institute of Health and Welfare. Health expenditure Australia 2014-15, Health and Welfare Expenditure Series no. 57. Cat. no. HWE 67. Canberra: Australian Institute of Health and Welfare; 2016

8. Biggs A. Dental reform: an overview of universal dental schemes. Canberra: Commonwealth of Australia; 2012.
9. Crocombe LA, Kraatz J, Hoang H, Qin D, Godwin D. Costly chronic diseases: a retrospective analysis of Chronic Disease Dental Scheme expenditure. Aust Health Rev. 2015;39(4):448-52.

10. Kraatz J, Qin D, Hoang H, Godwin D, Crocombe LA. Regional use of the Australian Chronic Disease Dental Scheme. Aust J Rural Health. 2014;22(6):310-5.

11. Skinner JC, List $P$, Wright C. Utilisation of the Medicare Teen Dental Plan in NSW, 2008-2010. N S W Public Health Bull. 2012;23(1/2):5-11.

12. Australian Government. Report on the Review of the Dental Benefits Act 2008. Canberra: Commonwealth of Australia; 2009.

13. Australian Government. ANAO Report No.12 2015-16. Administration of the Child Dental Benefits Schedule. Canberra: Australian National Audit Office, Commonwealth of Australia; 2015.

14. Australian Government. Report on the Third Review of the Dental Benefits Act 2008. Canberra: Department of Health, Commonwealth of Australia; 2016.

15. Nguyen TM. Is the current model of public dental care promoting the oral health of young children in Australia? Canberra: Deeble Institute, Australian Healthcare and Hospitals Association; 2017.

16. Do L, Spencer AJ, editors. Oral health of Australian children: the National Child Oral Health Study 2012-14. Adelaide: University of Adeliade Press; 2016

17. Teusner D, Amarasena N, Satur S, Chrisopoulos S, Brennan D. Applied scope of practice of oral health therapists, dental hygienists and dental therapists. Aust Dent J. 2016;61:342-9.

18. Teusner DN, Amarasena N, Satur J, Chrisopoulos S, Brennan DS. Dental service provision by oral health therapists, dental hygienists and dental therapists in Australia: implications for workforce modelling. Community Dent Health. 2016;33(1):15-22.

19. Mathu-Muju K, Friedman J, Nash D. Oral health care for children in countries using dental therapists in public, school-based programs, contrasted with that of the United States, using dentists in a private practice model. Am J Public Health. 2013;103(9):e7-e13.

20. Nash D, Mathu-Muju K, Friedman J. Ensuring access to oral health care for children: school-based care by dental therapists - a commentary. J Sch Health. 2015:85(10):659-62

21. Health Workforce Australia. Scope of practice review - Oral Health Practitioners. Adelaide: Health Workforce Australia; 2011.

22. Victorian Auditor-General's Office. Access to public dental services in Victoria, PP No 227. Melbourne: Victorian Government Printer; 2016.

23. Productivity Commission. Introducing competition and informed user choice into human services: reforms to human services. Melbourne: Productivity Commission, Commonwealth of Australia; 2018.

24. Dental Board of Australia. Dental Practitioner Registrant Data: December 2013. Melbourne: Australian Health Practitioner Regulation Agency; 2014

25. Australian Government. Department of Human Services. Medicare Item Reports. 2016; http://medicarestatistics.humanservices.gov.au/statistics/mbs item.jsp. Accessed 13 Dec 2016.

26. Health Workforce Australia. Australia's Future Health Workforce - Oral Health - Detailed Report. Adelaide: Health Workforce Australia; 2014

27. Baltutis L, Morgan M. The changing role of dental auxiliaries: a literature review. Aust Dent J. 1998;43(5):354-8.

28. Estai M, Kruger $\mathrm{E}$, Tennant M. Role of telemedicine and mid-level dental providers in expanding dental-care access: potential application in rural Australia. Int Dent J. 2016:66(4):195.

29. Freeman R, Lush C, MacGillveray S, Themessl-Huber M, Richards D. Dental therapists/hygienists working in remote-rural primary care: a structured review of effectiveness, efficiency, sustainability, acceptability and affordability. Int Dent J. 2013;63(2):103-12.

30. Gallagher J, Lim Z, Harper P. Workforce skill mix: modelling the potential for dental therapists in state-funded primary dental care. Int Dent J. 2013;63(2):57-64.

31. Harper P, Kleinman E, Gallagher J, Knight V. Cost-effective workforce planning: optimising the dental team skill-mix for England. J Enterp Inf Manag. 2013;26(1/2):91-108.

32. Wanyonyi $\mathrm{KL}$, Radford DR, Harper PR, Gallagher JE. Alternative scenarios: harnessing mid-level providers and evidence-based practice in primary dental care in England through operational research. Hum Resour Health. 2015:13(1):1-12

33. Conrad D, Lee R, Milgrom P, Huebner C. Estimating determinants of dentist productivity: new evidence. J Public Health Dent. 2010;70(4):262-8.

34. Beazoglou T, Chen L, Lazar V, Brown L, Ray S, Heffley D, Berg R, Bailit H. Expanded function allied dental personnel and dental practice productivity and efficiency. J Dent Educ. 2012;76(8):1054-60. 
35. Bailit H, Beazoglou T, DeVitto J, McGowan T, Myne-Joslin V. Impact of dental therapists on productivity and finances: I. Literature Review. J Dent Educ 2012;76(8):1061-7.

36. Brickle CM, Self KD. Dental therapists as new Oral health practitioners: increasing access for underserved populations. J Dent Educ. 2017;81(9):eS65-72.

37. Koppelman J, Vitzthum K, Simon L. Expanding where dental therapists can practice could increase Americans' access to cost-efficient care. Health Aff. 2016;35(12):2200-6.

38. Duckett $\mathrm{S}$, Cowgill M, Swerissen H. Filling the gap: a universal dental scheme for Australia. Melbourne: Grattan Institute; 2019.

39. Nguyen TM, Morgan M, Koshy S, Mathew S, Lew S. Revisiting the value of school dental check-up programs. Aust N Z J Oral Health Ther. 2015;(2):5-8.

40. Nguyen TM, Hsueh Y-S, Morgan M, Mariño R, Koshy S. Economic evaluation of the pilot children's dental program. J Dent Res Clin Transl Res. 2017;2(3):214-22.

41. Slade G, Bailie R, Roberts-Thomson K, Leach A, Raye I, Endean C, Simmons B, Morris P. Effect of health promotion and fluoride varnish on dental caries among Australian Aboriginal children: results from a community-randomized controlled trial. Community Dent Oral Epidemiol. 2011;39:29-43.

42. Divaris K, Preisser JS, Slade GD. Surface-specific efficacy of fluoride varnish in caries prevention in the primary dentition: results of a community randomized clinical trial. Caries Res. 2013:47(1):78-87.

43. Achembong LN, Kranz AM, Rozier RG. Office-based preventive dental program and statewide trends in dental caries. Pediatrics. 2014;133(4):e827-34.

44. Biordi DL, Heitzer M, Mundy E, DiMarco M, Thacker S, Taylor E, Huff M, Marino D, Fitzgerald K. Improving access and provision of preventive oral health care for very young, poor, and low-income children through a new interdisciplinary partnership. Am J Public Health. 2015;105(S2):e23-9.

45. Herndon JB, Tomar SL, Catalanotto FA, Vogel WB, Shenkman EA. The effect of Medicaid primary care provider reimbursement on access to early childhood caries preventive services. Health Serv Res. 2015:50(1):136-60.

46. Pahel BT, Rozier RG, Stearns SC, Quinonez RB. Effectiveness of preventive dental treatments by physicians for young medicaid enrollees. Pediatrics. 2011;127(3):e682-9.

47. Grant JS, Roberts MW, Brown WD, Quinonez RB. Integrating dental screening and fluoride varnish application into a pediatric residency outpatient program: clinical and financial implications. J Clin Pediatr Dent. 2007;31(3):175-8

48. Kranz AM, Lee J, Divaris K, Baker AD, Vann W Jr. North Carolina physicianbased preventive oral health services improve access and use among young Medicaid enrollees. Health Aff. 2014;33(12):2144-52.

49. Gnich W, Conway DI, Deas L, Mackenzie S, Burns J. Extending dental nurses' duties: a national survey investigating skill-mix in Scotland's child oral health improvement programme (Childsmile). BMC Oral Health. 2014;14:137.

50. Wu O, Wright W, Turner S, Anopa Y, Conway DI, Macpherson LMD, McMahon AD, Mclntosh E, Wu O. Comparison of the caries-protective effect of fluoride varnish with treatment as usual in nursery school attendees receiving preventive oral health support through the Childsmile oral health improvement programme - the Protecting Teeth@3 Study: a randomised controlled trial. BMC Oral Health. 2015;15:160.

51. Zhou Y, Forbes GM, Macpherson LMD, Ball GE, Humphris GM. The behaviour of extended duties dental nurses and the acceptance of fluoride varnish application in preschool children. Br Dent J. 2012;213(12):603-9.

52. Bergstrom E-K, Skold UM, Birkhed D, Lepp M. Dental nurses' experiences of performing a school-based fluoride varnish programme for children and adolescents in Sweden. Swed Dent J. 2016;40(2):181-90.

53. Hall M, Christian B. A health-promoting community dental service in Melbourne, Victoria, Australia: protocol for the North Richmond model of oral health care. Aust J Prim Health. 2017;23:407-14.

54. Dudko Y, Kruger E, Tennant M. National dental waitlists: what would it take to reset to zero? Aust Health Rev. 2016;40(3):277-81.

55. Chalmers NI, Compton RD. Children's access to dental care affected by reimbursement rates, dentist density, and dentist participation in Medicaid. Am J Public Health. 2017;107(10):1612-4.

56. Nash D, Friedman J, Mathu-Muju K, Robinson P, Satur J, Moffat S, Kardos R, Lo E, Wong A, Jaafar N, van den Heuvel J, Phantumvanit P, Chu E, Naidu R, Naidoo L, McKenzie I, Fernando E. A review of the global literature on dental therapists. Community Dent Oral Epidemiol. 2014;42(1):1-10.

57. Fair Work Commission. ACT Public Sector Health Professional Enterprise Agreement 2013-17. Commonwealth Government Printer; 2014.

58. Industrial Relations Commission of New South Wales. Health Professiona and Medical Salaries (State) Award. 2012.
59. Industrial Relations Commission of New South Wales. Health Employees Dental Officers (State) Award. 2015

60. Northern Territory Commissioner for Public Employment and Employees. Northern Territory Public Sector 2013-2017 Enterprise Agreement. 2013.

61. Fair Work Australia. Northern Territory Public Sector Dental Officers' 20112014 Enterprise Agreement. Commonwealth Government Printer; 2011.

62. Queensland Industrial Relations Commission. Health Practitioners and Dental Officers (Queensland Health) Award - State. 2015.

63. South Australia industrial relations commission. South Australian Public Sector Wages Parity Enterprise Agreement: Salaried 2014. Department of the Premier and Cabinet (Officer for the Public Sector); 2014.

64. Tasmanian Industrial Commission. Health and Human Services (Tasmania State Service) Award. 2016.

65. Tasmanian industrial commission. Allied Health Professionals (Tasmanian State Service) Agreement 2012. 2012

66. Fair Work commission. General Dentists' Victorian Public Sector MultiEnterprise Agreement 2009-2013. 2009.

67. Fair Work commission. Victorian Public Health Sector (Dental Therapists Dental Hygienists and Oral Health Therapists') Enterprise Agreement 20132017. Commonwealth Government Printer; 2014.

68. Western Australian Industrial Relations Commission. Dental Officers' Industrial Agreement 2013. 2013.

69. Western Australian Industrial Relations Commission. Public Sector and Government Officers General Agreement 2014. 2015.

\section{Ready to submit your research? Choose BMC and benefit from:}

- fast, convenient online submission

- thorough peer review by experienced researchers in your field

- rapid publication on acceptance

- support for research data, including large and complex data types

- gold Open Access which fosters wider collaboration and increased citations

- maximum visibility for your research: over $100 \mathrm{M}$ website views per year

At $\mathrm{BMC}$, research is always in progress.

Learn more biomedcentral.com/submissions 